\title{
Selective Determination of Nickel(II) in Water, Effluent and Alloy Samples Using Isonicotinohydroxamic Acid as Analytical Reagent
}

\author{
RAGHUNATHAN MUTHUSELVI
}

Department of Chemistry, Sri. Meenakshi Government College for Women (Autonomous), Madurai- 625 002, Tamilnadu, India

muthuselviumashankar@gmail.com

Received 28 April 2013 / Accepted 7 June 2013

\begin{abstract}
A simple and rapid spectrophotometeric procedure has been established for quantization of $\mathrm{Ni}(\mathrm{II})$ at trace levels. The reagent isonicotinohydroxamic acid (INHA) reacts with nickel(II) at $\mathrm{pH}<10$ and form a 1:2 lemon green complex. The complex has a maximum absorption at $610 \mathrm{~nm}$ with the molar absorptivity of $1.44 \times 10^{4} \mathrm{~L} \mathrm{~mol}^{-1} \mathrm{~cm}^{-1}$. Beer's law is obeyed over the range of $0.32-4.80 \mu \mathrm{gmL}^{-1}$. The Sandell's sensitivity for 0.001 absorbance unit is $4 \times 10^{-3} \mu \mathrm{gcm}^{-2}$. The relative standard deviation at $3.20 \mu \mathrm{gmL}^{-1}$ is $1.1 \%(\mathrm{n}=6)$. The tolerance limits for interfering ions are discussed. All variables were studied in order to optimize the reaction conditions. The efficacy of the proposed method is shown by the successful application of determining nickel in water, wastewater and alloy and the accuracy was determined by recovery experiment.
\end{abstract}

Keywords: Spectrophotometry Nickel, INHA

\section{Introduction}

Nickel is widely used in electroplating, in the manufacture of Ni-Cd batteries, rods for arc welding, pigments of paints, ceramic, surgical and dental prostheses, magnetic tapes, computer components and as nickel catalysts. Nickel enters waters from dissolution of industrial processes and waste disposal ${ }^{1}$. Nickel was thought to be essential for plants and some domestic animals, but not considered to be a metal of biological importance until 1975, when Zerner discovered that urease was a nickel enzyme ${ }^{2}$. Jack beans and soybeans generally contain high concentration of nickel. Compared with other transition metals, nickel is moderately toxic element, and still at low concentration produces a general toxic effect on the human organism, causing nasopharynx and lung diseases, malignant tumors and dermatological disease ${ }^{3}$. Nickel containing sewage is harmful after ingress into water. This fact explains the importance and need of monitoring nickel concentration in natural and waste water samples.

Flame and graphite furnace atomic absorption spectrometry and spectrophotometric methods provides accurate and rapid determination of metals in natural and waste waters ${ }^{4}$. 
Many classical ligands such as dimethylglyoxime, dithizone, and sodium-diethyldithiocarbamate are known for spectrophotometric determination of nickel ${ }^{5,6}$. Some of them are sensitive $e^{7,8}$, some are less selective ${ }^{9,10}$, while others are extracted into carcinogenic organic solvents ${ }^{11}$. In routine analysis, spectrophotometric methods are versatile and economical especially for developing countries.

Hydroxamic acids having one or more $-\mathrm{CONHOH}$ groups have been extensively studied as a consequence of their biological importance which is related to their ability to form metal ion complexes. Hydroxamic acids and other compound containing the hydroxamate group are ubiquitous in nature and are ultimately associated with iron transport in bacteria. Considerable interest seen in the coordination chemistry of the hydroxamic acids is also because of their relevance in the physiological systems in general and because of their siderophoric activities in microbial transport of iron and their theraputic applications in particular. Hydroxamic acids are known to bind to metal ions usually as a bidentate $\mathrm{O}, \mathrm{O}$-donor forming a five-membered chelate ring. With regard to the above relevance it is worthwhile to consider isonicotino-hydroxamic acid as analytical reagent for nickel, as hydroxamates are very effective metal-ion chelators. The strong ability of hydroxamic acids to form chelates, clarification of their interaction with metal ions is of particular importance and interest in terms of biological effects.

The present paper reports isonicotinohydroxamic acid(INHA) as an analytical reagent for the micro determination of nickel(II). The reaction has been studied in order to establish if it could be developed into a simple, quick and precise method for the spectrophotometric determination of trace amounts of nickel.

\section{Experimental}

All chemicals/solvents used were of analytical reagent grade or the highest purity available. Doubly distilled de-ionized water, which is non-absorbent under ultraviolet radiation, was used throughout. Glass vessels were cleaned by soaking in acidified solutions of $\mathrm{KMnO}_{4}$ or $\mathrm{K}_{2} \mathrm{Cr}_{2} \mathrm{O}_{7}$, followed by washing with concentrated $\mathrm{HNO}_{3}$ and rinsed several times with deionized water.

\section{Apparatus}

The absorbance and $\mathrm{pH}$ measurements were made on a Systronics spectrophotometer fitted with $1 \mathrm{~cm}$ tubular glass cells and Elico digital $\mathrm{pH}$ meter, respectively.

\section{Reagents}

Unless otherwise stated, all chemicals used were of analytical-reagent grade. Doubly distilled water was used for preparing aqueous solutions.

\section{The nickel(II) solution}

A $0.0805 \mathrm{~g} \mathrm{Ni}\left(\mathrm{NO}_{3}\right)_{2} \cdot 6 \mathrm{H}_{2} \mathrm{O}$ was dissolved in doubly distilled water containing few drops of conc. $\mathrm{HNO}_{3}$ in a $100 \mathrm{~mL}$ standard flask to get $1.38 \times 10^{-3} \mathrm{M}$ solution which is then standardized gravimetrically using dimethyl glyoxime. The working solutions were prepared daily by diluting the stock solution to an appropriate volume. All other chemicals used were of analytical grade.

\section{INHA}

The reagent (INHA) was prepared by the reported procedure ${ }^{12}$ and a $1 \times 10^{-3} \mathrm{M}$ solution of INHA in ethanol was used in the present studies. 


\section{The buffer solution}

The buffer solutions were prepared by mixing $1 \mathrm{M}$ hydrochloric acid-1 $\mathrm{M}$ sodium acetate ( $\mathrm{pH}$ 1.0-3.0), 0.2 M acetic acid-0.2 M sodium acetate ( $\mathrm{pH}$ 3.5-7.0). The ammonium buffer ( $\mathrm{pH} \sim 8.0 \pm 0.5$ ) was prepared by dissolving $6.75 \mathrm{~g}$ of ammonium chloride in $500 \mathrm{~mL}$ of doubly distilled water, adding $57 \mathrm{~mL}$ of concentrated ammonia and diluting to one liter with water. A $0.1 \mathrm{~N}$ borax buffer solution was prepared for $\mathrm{pH}>8$. $\mathrm{pH}$ of these solutions was checked with a $\mathrm{pH}$ meter.

\section{Determination of nickel(II)}

In different sets of $25 \mathrm{~mL}$ volumetric flasks, $1 \mathrm{~mL}$ of buffer solution(pH 8.5), $1.0 \mathrm{~mL}$ of $10 \% \mathrm{w} / \mathrm{v}$ sodium hydrogen carbonate, $2 \mathrm{~mL}$ of INHA $\left(1 \times 10^{-3} \mathrm{M}\right)$ and varying volumes of $1.38 \times 10^{-4} \mathrm{M}$ nickel(II) solution, were added and then made up to the mark with doubly distilled water. The absorbance was measured at $610 \mathrm{~nm}$ against the reagent blank, and the calibration plot was prepared. The calibration graph follows the straight line equation, $\mathrm{y}=\mathrm{mc}+\mathrm{b}$; where $\mathrm{c}$ is the concentration of the solution, $\mathrm{y}$ is measured absorbance or peak height, $\mathrm{m}$ and $\mathrm{b}$ are constants.

\section{Results and Discussion}

\section{Absorption spectra}

The absorption spectra of INHA and its nickel(II) complex [Ni-INHA] was recorded in the wavelength range $350-800 \mathrm{~nm}$ at a $\mathrm{pH} 8.5$ against the reagent blank. The spectra showed that the nickel(II) complex has an absorption maxima at $610 \mathrm{~nm}$. The maximum absorbance value corresponds to a mole ratio $\left[\mathrm{Ni}^{2+}\right] /[\mathrm{INHA}]$ of $1: 2$ which supports a $\mathrm{NiL}_{2}$ stoichiometry. At $610 \mathrm{~nm}$, the complex shows large absorbance while the reagent blank shows negligible absorbance. Hence, analytical studies were carried out at $610 \mathrm{~nm}$.

\section{Effect of $p H$}

The effect of $\mathrm{pH}$ on the colour formation was studied to arrive at the optimum $\mathrm{pH}$. Plot between $\mathrm{pH}$ and absorbance shows that maximum colour was that obtained in the $\mathrm{pH}$ range of 8.0-9.0. Therefore, $\mathrm{pH} 8.5$ was chosen for further studies.

\section{Effect of INHA concentration}

The optimum concentration of reagent required for the maximum colour formation was studied by measuring the absorbance at $610 \mathrm{~nm}$. The results indicate that a 20 fold molar excess of the reagent is essential to get maximum absorbance.

\section{Effect of time and stability}

The reaction between nickel(II) and INHA was instantaneous at room temperature and the absorbance of the complex remained constant for more than $48 \mathrm{~h}$.

\section{Composition of the complex}

The composition of the complexes was studied in the excess of Ethanol water solutions by the mole-ratio method. A break at a 1:2 (M:L) mole ratio suggested the formation of $\mathrm{M}(\mathrm{RCONHO}) \mathrm{n}$, where $\mathrm{n}$ is a neutral monodentate ligand.

\section{Analytical performance}

Performance characteristic of the developed technique was obtained from the standard solution of nickel. For an aqueous volume of $25 \mathrm{~mL}$ the calibration graph exhibited linearity over the range of $0.32-4.80 \mu \mathrm{g} / \mathrm{mL}$ and the determinations were carried out in the range 
1.60-3.20 $\mu \mathrm{g} / \mathrm{mL}$. The Sandell's sensitivity for 0.001 absorbance was $4.0 \times 10^{-4} \mu \mathrm{gcm}^{-2}$. The relative standard deviation $\left(95 \%\right.$ confidence level) for $3.20 \mu \mathrm{gmL}^{-1}$ of nickel was found to be $1.1 \%(n=6)$. The overall physicochemical and analytical properties of nickel(II) complex with INHA is summarized in Table 1 . And the results of the determinations of analytical performance are given in Tables 2 and 3. It was found that the order of addition of reactants has no effect on the formation of the complex.

Table 1. Physicochemical and analytical properties of nickel(II) complex with INHA

\begin{tabular}{cll}
\hline S.No. & \multicolumn{1}{c}{ Characteristics of Ni-INHA } \\
\hline 1. & $\lambda_{\max }, \mathrm{nm}$ & 610 \\
2. & pHrange (optimum) & 8.5 \\
3. & Mole of reagent required per mole & 20 -fold \\
& of metal ion for full colour development \\
4. & Time stability of the complex (in hours) & 48 \\
5. & Beer's law validity range, $\mu \mathrm{g} / \mathrm{mL}^{-1}$ & $0.32-4.80$ \\
6. & Molar absorptivity, $\mathrm{L} \mathrm{mol}^{-1} \mathrm{~cm}^{-1}$ & $1.44 \times 10^{4}$ \\
7. & Sandell's sensitivity, $\mu \mathrm{g} \mathrm{of} \mathrm{Ni}(\mathrm{II}) \mathrm{mL}^{-1}$ & $4.0 \times 10^{-4}$ \\
8. & Composition of the complex as obtained & $1: 2$ \\
& in Job's and molar ratio methods (M:L) \\
10. & Standard deviation & 0.548 \\
\hline
\end{tabular}

Table 2. Determination of nickel(II)

\begin{tabular}{cccccccc}
\hline \multicolumn{3}{c}{ INHA method } & \multicolumn{5}{c}{ DMG method } \\
\hline \multirow{2}{*}{ S.No } & $\begin{array}{c}\text { Ni(II) taken } \\
\mu \mathrm{g} \mathrm{mL}^{-1}\end{array}$ & $\begin{array}{c}\mathrm{Ni}(\mathrm{II}) \text { found } \\
\mu \mathrm{g} \mathrm{mL} \mathrm{mL}^{-1}\end{array}$ & $\begin{array}{c}\text { Recovery } \\
\%\end{array}$ & $\begin{array}{c}\text { Error } \\
\%\end{array}$ & $\begin{array}{c}\text { Ni(II) } \\
\text { found }\end{array}$ & $\begin{array}{c}\text { Recovery } \\
\%\end{array}$ & $\begin{array}{c}\text { Error } \\
\%\end{array}$ \\
\hline 1 & 1.60 & 1.59 & 99.4 & 06 & 1.61 & 100.6 & 0.6 \\
2 & 1.92 & 1.91 & 99.5 & 05 & 1.93 & 100.5 & 0.5 \\
3 & 2.24 & 2.25 & 100.4 & 09 & 2.26 & 100.9 & 0.9 \\
4 & 2.56 & 2.55 & 99.6 & 04 & 2.54 & 99.2 & 0.8 \\
5 & 2.88 & 2.89 & 100.3 & 0.3 & 2.90 & 100.7 & 0.7 \\
6 & 3.20 & 3.21 & 100.3 & 0.3 & 3.23 & 100.9 & 0.9 \\
\hline
\end{tabular}

Table 3. Statistical comparison

\begin{tabular}{clccc}
\hline S.No & \multicolumn{1}{|c}{ Method } & $\begin{array}{c}\text { av. } \\
\text { error* \% }\end{array}$ & $\begin{array}{c}\text { S.D* } \\
\%\end{array}$ & C.V* \\
\hline 1 & Isonicotinohydroxamic acid(INHA) & 0.50 & 0.548 & 0.228 \\
2 & Dimethylglyoxime & 0.73 & 0.5510229 & \\
\hline
\end{tabular}

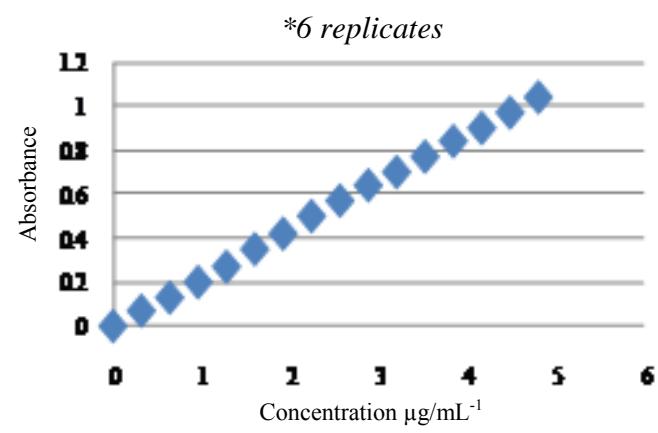

Figure 1. Validity of Beer's Law 


\begin{abstract}
Absorbance
Effect of foreign ions

The effect of various ions on the determination of nickel with INHA at a fixed concentration of nickel $\left(2.56 \mu \mathrm{g} \mathrm{mL}^{-1}\right)$ and in the presence of different amounts of foreign ions was studied. An error of $\pm 5 \%$ in absorbance was considered tolerable. The results are summarized in Table 4 and indicate that at the given level there is no significant interference with the spectrophotometric determination of nickel. A few metals that interfered were masked and then determined for nickel.
\end{abstract}

Table 4. Interference studies; amount of nickel(II) taken-2.56 $\mathrm{g} \mathrm{L}^{-1}$

\begin{tabular}{|c|c|}
\hline Foreign Ions, $\mu \mathrm{g} \mathrm{mL}^{-1}$ & Tolerance Limit \\
\hline Nitrate & 500 \\
\hline Sulphate and sodium(I) & 250 \\
\hline Barium(II) & 125 \\
\hline Chloride and Ammonium(I) & 100 \\
\hline Hydroxide and magnesium(II) & 75 \\
\hline Phosphate, calcium(II) and potassium(I) & 40 \\
\hline Lead(II), zinc(II) a , chromium(III) and cadmium(II) & 10 \\
\hline $\begin{array}{l}\text { EDTA, molybdate, citrate, tartarate, oxalate, borate, } \\
\text { iron(III) })^{\mathrm{a}}, \text { mercury(II) }{ }^{\mathrm{b}} \text { and manganese(II) }\end{array}$ & 08 \\
\hline 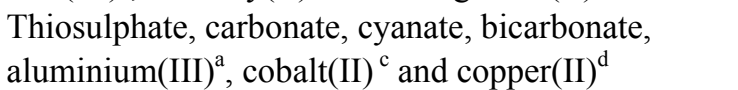 & 04 \\
\hline
\end{tabular}

\title{
Applications
}

\section{In natural water and industrial effluent (waste water) samples}

To confirm the usefulness of the proposed method, it was applied to the determination of nickel in natural water, industrial effluent samples. In view of the unknown composition of natural water and effluent samples, the same equivalent portions of each sample were analyzed for nickel content; the recoveries in the "spiked" (added to the samples before the mineralization or dissolution) samples are in good agreement (Table 5,6 and 7). For this purpose the first two samples were first filtered through a Millipore $0.45 \mu \mathrm{m}$ pore-size membrane into previously cleaned polyethylene bottles and were then treated according to the given procedure.

Table 5. Determination of nickel(II) in natural water sample

\begin{tabular}{cccc}
\hline S. No. & Ni(II) added, $\mu \mathrm{g} \mathrm{mL}^{-1}$ & $\mathrm{Ni}(\mathrm{II})$ found, $\mu \mathrm{g} \mathrm{mL}^{-1}$ & Recovery, $\%$ \\
\hline 1. & 1.60 & 1.61 & 100.6 \\
2. & 1.92 & 1.93 & 100.5 \\
3. & 2.24 & 2.26 & 100.9 \\
4. & 2.56 & 2.58 & 100.8 \\
5. & 2.88 & 2.90 & 100.7 \\
6. & 3.20 & 3.21 & 100.3 \\
\hline
\end{tabular}


Table 6. Determination of nickel(II) in effluent sample

\begin{tabular}{cccc}
\hline S.No. & $\mathrm{Ni}(\mathrm{II})$ added, $\mu \mathrm{g} \mathrm{mL}^{-1}$ & $\mathrm{Ni}(\mathrm{II})$ found, $\mu \mathrm{g} \mathrm{mL} \mathrm{m}^{-1}$ & Recovery, $\%$ \\
\hline 1. & 1.60 & 1.58 & 98.7 \\
2. & 1.92 & 1.91 & 99.5 \\
3. & 2.24 & 2.25 & 100.4 \\
4. & 2.56 & 2.57 & 100.4 \\
5. & 2.88 & 2.87 & 99.6 \\
6. & 3.20 & 3.22 & 100.6 \\
\hline
\end{tabular}

Table 7. Alloy analysis: Determination of nickel(II) in nichrome

\begin{tabular}{ccccccc}
\hline Sample composition, \% & $\begin{array}{c}\text { certified } \\
\text { value* } \\
\text { Ni \% }\end{array}$ & S.No. & $\begin{array}{c}\text { amount } \\
\text { of alloy } \\
\text { taken }\end{array}$ & $\begin{array}{c}\text { amount } \\
\text { of Ni(II) } \\
\text { found }\end{array}$ & $\begin{array}{c}\text { amount } \\
\text { of Ni(II) } \\
\text { found }\end{array}$ & $\begin{array}{c}\text { av. } \\
\text { Ni(II) } \\
\text { found }\end{array}$ \\
\hline Nichrome & & 1 & 1.17 & 0.69 & 59.87 & \\
(Cr-12, Ni-60, & 60.0 & 2 & 2.35 & 1.40 & 59.57 & \\
Fe - 26, Mn-2) & & 4 & 3.51 & 2.12 & 60.40 & 59.72 \\
& & 5 & 5.68 & 2.80 & 59.82 & \\
& & 6 & 7.02 & 3.46 & 59.14 & \\
\hline
\end{tabular}

\section{In alloy sample}

$0.1 \mathrm{~g}$ of Steel sample was dissolved completely in minimum amount of aqua-regia by slow heating on sand bath and then heated to fumes of oxides of nitrogen. After cooling, 5-10 mL of 1:1- $\mathrm{H}_{2} \mathrm{O}: \mathrm{H}_{2} \mathrm{SO}_{4}$ mixture was added and evaporated to dryness. Sulphuric acid treatment was repeated three times to remove all the nitric acid. The residue was dissolved in $20 \mathrm{~mL}$ of distilled water, filtered and the filtrate was made up to $100 \mathrm{~mL}$ in a calibrated volumetric flask with distilled water. The sample solution was appropriately diluted to obtain the concentrations in the required range.

\section{Conclusion}

INHA provides a simple, rapid, sensitive and selective method for the spectrophotometric determination of nickel(II). The main advantage of the proposed method is its rapidity, as the colour development is instantaneous at room temperature. It does not require heating, cooling, or long standing to record constant absorbance or extraction with a solvent or addition of a surfactant to intensify the colour of the system, which is an inevitable part of quite a number of reported methods. Quite a number of cations and anions offer no interference except a few, so the results of the investigations are highly fruitful with a considerably high value of molar absorptivity, accuracy and precision and it is hoped that this method can be suggested for the routine analysis of nickel(II).

\section{Acknowledgement}

The author would like to extend her appreciation to the University Grants Commission (SERO), Hyderabad, for their financial support of this work. The author also expresses her heartfelt gratitude to the Principal of the College and the Head, Department of Chemistry, Sri. Meenakshi Government College for Women(Autonomous), Madurai, for their valuable guidance and support. 


\section{References}

1. Merian E, Anke $M$ and Stoppler M, Elements and Their Compounds in the Environment, Vol. 2, Wiley, VCH: 2004, Weinheim.

2. Zerner B, Bioorg Chem., 1991, 19(1), 116-131. DOI:10.1016/0045-2068(91)90048-T.

3. Templeton D, Biological Monitoring of Chemical Exposure in the Workplace, Word Health Organization, Geneva, 1990.

4. Franson M A H, Standard Methods for Examination of Water and Waste Water, American Publication Health Association; Washington, D.C., USA, 1995.

5. Onishi H, Photometric Determination of Traces of Metals, Wiley-Interscience, New York, 1984.

6. Marczenko Z, Separation and Spectrophotometric Determination of Elements, Ellis Harwood, New York, 1986.

7. Ferreira S L C, Santos B F, de Andrade J B and Spinola Costa A C, Microchim Acta, 1996, 122(1-2), 109-115; DOI:10.1007/BF01252412.

8. Malik A K, Kaul K N, Lark B S, Faube W and Rao A L J, Turk J Chem., 2001, 25(1), 99-105.

9. Kumar A and Jain M, Chem Anal., 1992, 39, 73.

10. Bansal A K and Nagar M, J Indian Chem Soc., 2006, 83, 731.

11. Odashima T, Kohata K, Yogi K and Ishii H, Bunseki Kagaku, 1995, 44(2), 135-138.

12. Aliyu A O, Egwaikhide A P and Gimba C E, Sci World J., 2008, 3(2). 